\title{
The Snare of Systemic Racism and Other Challenges Confronting Hip-Hop Based Pedagogy
}

\begin{abstract}
Name: Jomo W. Mutegi
Indiana University, IUPUI

Email Address: jmutegi@iupui.edu

Phone: $317-278-4202$

Mailing Address: 902 W. New York Street, ES 1115, Indianapolis, IN 46202

Biographical Statement: Jomo W. Mutegi is an Associate Professor in the Indiana University School of Education at IUPUI, and Principal Investigator of the (ES) ${ }^{2}$ STEM Learning Lab. He is also PI of CTI Inspire, a National Science Foundation supported effort designed to prepare pre-service teachers to serve urban students through a culturally responsive and socially transformative education His research foregrounds racism and socially transformative STEM education for people of African descent. Recent publications include: “'Life's First Need Is for Us to be Realistic' and Other Reasons for Examining the Sociohistorical Construction of Race in the Science Performance of African American Students" in the Journal of Research in Science Teaching (2013); and "Tales from the mic: A content analysis of 10 years of hip-hop lyrics" in the journal African American Learners (2014).
\end{abstract}

Name: Jada A. Phelps-Moultrie Michigan State University

Email Address: jada@msu.edu

Phone: Contact lead author

Mailing Address: Contact lead author

Biographical Statement: Jada A. Phelps-Moultrie is an Assistant Professor of Educational Leadership at Michigan State University. Her research explores the dual phenomena of racial battle fatigue, and "parenting while Black." She also explores the role of school leaders in perpetuating or disrupting factors that marginalize Black children. Recent publications include: "Talk About a Racial Eclipse: Narratives of Institutional Evasion in an Urban SchoolUniversity Partnership" in the Journal of Cases in Educational Leadership (2017); and "An initial exploration of a community-based framework for educational equity with explicated exemplars" in the journal Race Ethnicity and Education (2017).

Name: Vanessa R. Pitts Bannister

Florida A\&M University

Email Address: vanessa.pittsbannister@famu.edu

Phone: Contact lead author

Mailing Address: Contact lead author

Biographical Statement: Vanessa R. Pitts Bannister is an Associate Professor and Coordinator of Mathematics Education at the Florida Agricultural and Mechanical University (FAMU). Recently, she was the PI of a Helios Grant program that aimed to improve STEM education through innovative integration and application of proven strategies through coursework and/or professional development. Before this grant, she completed an NSF-funded study of pre-service secondary mathematics teachers' interactions with reform curriculum materials in mathematics methods courses. This line of work resulted in a co-edited book and other peer-reviewed publications. Her research interests include teacher and student knowledge in areas of algebra and rational numbers, teachers' pedagogical and content knowledge with respect to curriculum materials, and equity and diversity issues in mathematics education.

Brief Description of Article: The objective of this article is to promote critical discourse around the conceptualization and implementation of hip-hop based pedagogy by (a) identifying a set of challenges presented in the conceptualization of HHBP scholarship, (b) describing the narrative that these challenges converge to support, and (c) suggesting an alternative narrative aimed at fostering a more empowering use of hip-hop based pedagogy.

This is the author's manuscript of the article published in final edited form as:

Mutegi, J. W., Phelps-Moultrie, J. A., \& Pitts Bannister, V. R. (2018). The snare of systemic racism and other challenges confronting hip-hopbased pedagogy. Teachers College Record, 120(11). https://www.tcrecord.org ID Number: 22461 
The Snare of Systemic Racism and Other Challenges Confronting Hip-Hop Based Pedagogy

\begin{abstract}

\section{Background}

Although there has been a pronounced growth in hip-hop based pedagogy (HHBP) scholarship in recent years, there has not been a concomitant critique of this growing body of work. As a consequence, much of this scholarship is best characterized as advocacy of hip-hop based pedagogy.
\end{abstract}

\title{
Purpose/Objective
}

The objective of this article is to promote critical discourse around the conceptualization and implementation of hip-hop based pedagogy by (a) identifying a set of challenges presented in the conceptualization of HHBP scholarship, (b) describing the narrative that these challenges converge to support, and (c) suggesting an alternative narrative aimed at fostering a more empowering use of hip-hop based pedagogy.

\section{Research Design}

To accomplish this objective, we provide an in-depth critique of Emdin and Lee's (2012) article, "Hip-hop, the 'Obama effect,' and urban science education.” Through this critique we first identify 8 challenges posed by the authors' argument, as well as the narrative that is the foundation of this argument.

\section{Conclusions/Recommendations}

We then conclude by presenting an alternate narrative of hip-hop as an instrument of systemic racism, and offering suggestions as to how hip-hop based pedagogy can be used in both research and practice to both avoid and counter systemic racism. 


\section{Executive Summary}

This article is aimed at advancing discourse around hip-hop based pedagogy to include more explicit and critical discussions of issues such as race, systemic racism, the role of hip-hop in maintaining disparate racial structures, and the influence of hip-hop on learners of African descent. In the article, we use Emdin and Lee's 2012 article, 'Hip-hop, the 'Obama effect,' and urban science education" as a starting point for advancing this discourse. The article unfolds in

three sections. In the first section, we draw from Emdin and Lee's article to identify a set of eight challenges presented in the conceptualization of HHBP scholarship. The first challenge, "The Use and Misuse of 'Urban',' is the need to more clearly identify the population of interest. Here we point to the tendency to characterize populations as "urban" without clearly operationalizing that construct. We also point to the tendency to uncritically (and perhaps inaccurately) conflate multiple characterizations of learners. The second challenge, "Head Nods and Hand Movements," is the need to more clearly identify the outcomes that could be expected by implementing hip-hop based pedagogy. Here the authors refer to students being "successful" without ever identifying what constitutes success.

The third challenge, "A Distinction Without a Difference," speaks to the need to more clearly distinguish "commercial” hip-hop from "non-commercial” hip-hop. Although hip-hop based pedagogy scholarship often claims that the two are distinct, it is difficult to find clear guidelines for making this distinction. The fourth challenge, "Tales of the Fringe," is the veracity of the claim that hip-hop exists at the fringes of modern Western society. Here we provide evidence which runs counter to this claim.

The fifth challenge, "Mistaken (Cultural) Identity?", is the claim that hip-hop is the 
culture of urban youth. Here we point to work which argues that hip-hop is one of many Western cultural artifacts that have been foist upon people of African descent. The sixth challenge, "Internal Inconsistency," speaks to instances in Emdin and Lee's article where there appear to be contradictory claims.

The seventh challenge, "Can’t We All Get Along," is the authors' characterization of hiphop as a racially unifying force. Here we point out that the authors offer no support for the idea that hip-hop is a unifying force among its consumers and practitioners. We also provide evidence that calls this idea into question. The eight challenge, “The Unfounded Perceptions of Hip-Hop's Negative Impact," speaks to the authors' claim that there is no basis for the idea that hip-hop has a negative impact on youth. Here we provide a sample of studies that demonstrate the negative impact of hip-hop on both thinking and behavior. These studies span a broad range of disciplinary areas.

Following the presentation of these eight challenges, the second section of the article aims to describe the narrative of hip-hop as presented by Emdin and Lee. That narrative presents hip-hop as a subculture started by "minoritized" young people in response to being locked out of mainstream social structures. The narrative suggests that the hip-hop subculture is a melting pot, which welcomes participants from many racial and ethnic backgrounds. These participants are drawn together by their shared experience of being marginalized in various ways and hip-hop offers a vehicle through which their voices can be heard. As the challenges presented in the first section demonstrate, this narrative is problematic, in that many of the supports for the narrative lack veracity. In addition, the narrative itself lacks explanatory power largely because it ignores the role of systemic racism

The third section of this article suggest an alternative narrative aimed at fostering a more 
empowering use of hip-hop based pedagogy. This alternative narrative presents hip-hop as an instrument of systemic racism. The alternative narrative re-presents some of the claims made by hip-hop based pedagogy advocates such that they are more consistent with available evidence. The article concludes with suggestions of how hip-hop based pedagogy can be used in both research and practice to counter systemic racism. 
The Snare of Systemic Racism and Other Challenges Confronting Hip-Hop Based Pedagogy

If you do not understand White Supremacy (Racism) - what it is, and how it works everything else that you understand will only confuse you.

Neely Fuller, Jr.

Recent years have seen a pronounced growth in examinations of hip-hop across a wide array of disciplines. In educational scholarship in particular, we find a broad range of both position papers and empirical studies. Among its many manifestations, this scholarship has examined the role of hip-hop as a cultural artifact for practicing and preservice teachers (Bridges, 2011; Petchauer, 2011; Pulido, 2009). It has argued for the use of hip-hop as a vehicle for curriculum development (Emdin, 2011; Stovall, 2006); and it has argued for inclusion of hip-hop in standard school curriculum on the basis that it is the culture of African American (or urban) youth (Ladson-Billings, 2013; Petchauer, 2011).

While there have been a few isolated efforts (e.g. Davis, Pitts-Bannister, and Mutegi, 2014; Gosa and Fields, 2012; Mutegi and Pitts Bannister, 2014), there has not been a sustained constructive critique of this work. Instead the overwhelming majority of this scholarship in education is best characterized as advocacy of hip-hop based pedagogy (HHBP). Given the sociohistorical context in which children of African descent are now educated (e.g. racial composition of the teaching workforce, disproportionate discipline of students of African descent, the school to prison pipeline) and the messaging of mainstream hip-hop music, it is imperative that there be ongoing critique of the use and implementation of hip-hop in classroom pedagogy. It is our contention that by advocating injudiciously for the implementation of hip-hop based pedagogy in schools, students of African descent may be made more vulnerable. 
In keeping with the spirit of constructive critique, the objective of the present article is to (a) identify a set of challenges presented in the conceptualization of HHBP scholarship, (b) describe the narrative that these challenges converge to support, and (c) suggest an alternative narrative aimed at fostering a more empowering use of hip-hop based pedagogy. To accomplish this objective, we provide an in-depth critique of one article by Emdin and Lee (2012), "Hip-hop, the 'Obama effect,' and urban science education." We selected this article in particular, as one that is representative of the types of constructs, conjectures and claims made in HHBP literature. The article begins with a summary and critique of the article by Emdin and Lee, followed by a description of an alternative way to conceptualize and present hip-hop in K-12 pedagogy.

In the article, "Hip-hop, the 'Obama effect,' and urban science education,” Emdin and Lee (2012) advance the argument that "urban youth of color" benefit when hip-hop is made central to their educational experience. The authors present their argument in five sections: a description of hip-hop; a presentation of four theoretical constructs; a description of the connections between hip-hop and science; a description of the "Obama effect"; and implications for improving educational practice. The article represents a refreshing addition to science education literature in that it foregrounds and draws our attention to the importance of students' lived experiences. In doing so, the authors draw from the spirit of culturally responsive teaching (Gay, 2010) in an effort to position teachers to be of better service to students who might come from different racial, ethnic or socioeconomic backgrounds.

While we do not disagree with the authors' goal of including hip hop as a component of standard school curriculum, we have noted several challenges confronting the authors' argument. We have organized these challenges into three categories: constructs, claims, and contradictions. What makes many of the constructs, claims, and contradictions problematic is that in addition to 
being either incomplete, unfounded, or poorly operationalized, they support a narrative that masks the various ways that hip-hop functions as an instrument of systemic racism. What is more, by being accepted uncritically, they divert our educational efforts away from working to understand how hip-hop is used to undermine people of African descent and what can be done about it.

In this article, we first identify 8 challenges posed by the authors' argument, as well as the narrative that is the foundation of this argument. We then conclude by (a) presenting an alternate narrative of hip-hop as an instrument of systemic racism and (b) offering suggestions as to how hip-hop based pedagogy can be used in both research and practice to both avoid and counter systemic racism. For clarity, we draw from Feagin \& Elias' (2013, p. 936) work as well as that of Frances Welsing (1995) and Neely Fuller (2016) to define systemic racism as the foundational, large-scale and hierarchical system of racial oppression devised and maintained by whites to conquer, suppress, and control non-white people.

\section{Problems}

\section{Constructs}

\section{Challenge \#1: The Use and Misuse of "Urban"}

The first challenge that we address is that of clearly identifying the population of interest. In their abstract, the authors suggest that the population of interest is urban youth, as they suggest that "By engaging in a concerted focus on hip-hop culture, science educators can connect urban

youth to science in ways that generate a genuine recognition of who they are..." (Emdin and Lee, 2012, p. 2). Although this construct is central to the article, the authors do not operationalize it. Is someone an urban youth by virtue of where they live? Where they attend school? Is the amount of time one lives or attends school in an urban setting a factor in determining whether 
one is considered an urban youth? How do normal life transitions affect one's status as an "urban" youth? The urban construct is not an unproblematic one, especially in educational research (Milner IV, 2012; Mutegi, 2013). So, in some ways the authors' failure to operationalize the urban construct reflects a problem that pervades educational research.

However, the authors exacerbate the problem of not operationalizing the urban construct by conflating multiple characterizations of the population of interest. Among these various characterizations, we find: "urban youth" (pp. 1, 2, 3, 4, 5, 7, 9, 10, 11, 12, 13, 14, 15, 16, 17, 18, 19, 20, 21), “urban marginalized youth" (p. 2), "urban youth of color" (pp. 2, 3, 11, 12, 16, 19), “minoritized urban youth" (p. 10), “marginalized youth" (pp. 3, 9), "Black \& Latino/a youth" (pp. 3, 13), "hip-hop youth” (pp. 1, 2, 3, 4, 6, 7, 8, 9, 10, 11, 12, 13, 14, 16, 17, 19, 20, 21), "minority" (p. 11), and "ethnic minority" (p. 10). There is no clear consistency in the varied use of these characterizations. Neither do the authors explain whether their multiple characterizations are invoked with intention, and if so, how. This conflation begs several conceptual questions. Are all urban youth viewed as hip-hop youth? Are Black and Latino/a youth assumed to be urban youth? How does the authors' argument speak to Black \& Latino/a youth from suburban or rural areas? How should we regard Asian youth? Are they marginalized? Minoritized? How do the authors regard White youth in urban settings? Are they also equated with urban youth of color or minoritized urban youth?

One consequence of failing to adequately operationalize this key construct, is that the authors allow "urban" to be read as a euphemism, which is a problematic tendency in educational scholarship (Hilliard, 1988, 1978; Mutegi, 2013; Watson, 2011). A second consequence is that "urban-ness" is treated as a fixed characteristic. In reality, however, people make frequent transitions across urban, suburban and rural boundaries as they live, work and play and as they 
progress through life stages. A third consequence is that "urban" carries an implied and inaccurate stereotype -- it connotes the tired, poor, homeless huddled masses. It connotes slums, ghettos, and shantytowns. It, shamefully and ironically, ignores the immense wealth that is generated in the heart of most major metropolitan cities and the residents who generate it. A fourth consequence is that by failing to adequately operationalize this key construct, the authors blur (and actually confuse) the significance of students' racial and ethnic group membership. It fosters the erroneous idea that urban (or marginalized, or minoritized, or hip-hop, or Asian, etc.) youth are at the same place socially and educationally.

\section{Challenge \#2: Head Nods and Hand Movements}

The second challenge confronting the authors' is the notion of success. The authors assert that, "...hip-hop culture has been proposed to be a means through which urban youth can find success in school" (Emdin and Lee, 2012, p. 1). Here again the notion of school success is poorly operationalized. In one instance, the authors describe a classroom where, “...traditional criteria for success are expanded...” as a place in which students, “...greet each other with head nods and elaborate handshakes, refer to rap songs while they engage in lab activities, or rest their safety goggles on the side of their heads..." (p. 11). In a second instance, the authors point to “...head nods and excited hand movements..." (p. 16) as well as increased instances of students speaking in class and raising their hands to answer questions (p. 17). These references seem to suggest that the authors associate success with increased engagement. However, if increased engagement is their measure of success, it is never addressed explicitly, neither is the notion of engagement unpacked.

The end goal of science instruction varies greatly among educators, and includes: those who advocate for science literacy in its many forms (American Association for the Advancement 
of Science, 1993; Lee, 1997), career preparation (Bhattacharyya, Mead, and Nathaniel, 2011; Riegle-Crumb, Moore, and Ramos-Wada, 2011), elimination of achievement disparities (Cohen, Garcia, Purdie-Vaughns, Apfel, and Brzustoski, 2009), social justice (Barton, 2002), and even upheaval of disparate social structures (Mutegi, 2011). Given this context, the authors' argument would be strengthened by reporting more explicitly what result we should reasonably expect from a class centered around HHBP beyond head nods and hand movements.

\section{Claims}

\section{Challenge \#3: A Distinction without a Difference}

The third challenge is the authors' effort to distinguish "commercial" hip-hop from "noncommercial" hip-hop. In making this claim, their argument is two-fold. First, they maintain that hip-hop is a set of cultural practices that involves more than rapping. In the first section of the article, What Is and Is Not Hip-Hop?, the authors explain that hip-hop includes "graffiti, breakdancing/b-boying, deejaying and rapping" (Emdin and Lee, 2012, p. 4). They go on to point out that most people only associate hip-hop with rapping because of its commercial appeal. Second, they maintain that the commercial rap with which many people are familiar is not an authentic representation of hip-hop. According to the authors, commercial forms of rap "involve superficial topics such as gross materialism," "gratuitous misogyny," and "violence". They contrast these forms of rap against "other versions of rap as hip-hop music, which are more true to hip-hop culture, more reflective of the realities of the urban youth experience, and more lyrically complex than commercialized forms" (p. 5).

In spite of their claim that there are lines of distinction between commercial and noncommercial hip-hop, the authors offer no clear guidelines for helping the reader to make this distinction. If anything, the article reinforces the idea that HHBP scholars are advocating for 
curricular acceptance of popular rap entertainers. Throughout this text in particular, the authors offer no examples of the importance or application of graffiti, breakdancing/b-boying, or deejaying to the classroom. They do offer examples of the importance of rappers to the classroom. For example, the authors share an anecdote about a ninth grader excited to have seen President Obama "dust his shoulders off."

The act of dusting one's shoulders off is a practice that was made famous by rapper Jay$\mathrm{Z}$, and is one that can be identified as distinctly hip-hop because of its prevalent use in hip-hop culture both before and after it was made famous by rapper Jay-Z (Emdin and Lee, 2012, p. 15).

In another instance, the authors describe a student's excitement after seeing an Obama supporter make a hand gesture that was mistaken for the Rock-A-Fella Records hand gesture. This gesture (in this context) was also popularized by Jay-Z (Emdin and Lee, 2012, p. 15). In a third instance the authors share an exchange with a student who expresses the idea that President Obama "gets us... he has a hip hop vibe... He has Jay-Z in his iPod" (p. 18).

What is telling here is that all the exemplars provided by the authors feature one rapper, Jay-Z, who by any conceivable measure (i.e. record sales, radio air play, net worth, endorsements, or music awards) would be considered commercial. Even the Rap Genius project (Leland, 2012) that lead author Emdin pioneers, is based on a partnership with GZA, another rapper and founding member of the Wu-Tang Clan, who by many measures would be considered commercial.

\section{Challenge \#4: Tales of the Fringe}

The fourth challenge is the authors' claim that hip-hop exists at the fringe of modern Western society. In one instance the authors characterize hip-hop as "lowbrow culture" (p. 10). 
Elsewhere they write that, "society at large persistently devalues hip-hop" (pp. 3, 19). The authors characterize hip-hop as, "an amalgamation of the thoughts, words, and behaviors/actions of those who dwell in urban settings and have traditionally been marginalized from socioeconomic and educational attainment" (p. 2). In short, the authors work to present hip-hop as an ostracized culture, as the purview of the downtrodden and dispossessed.

This presentation of hip-hop as a fringe cultural expression stands in stark contrast to available evidence. Hip-hop is arguably the biggest pop-culture phenomenon presently known. Several major Hollywood actors are current or former hip-hop performers (e.g. Ice Cube, Ice T, Will Smith, 50 Cent, Queen Latifa, Mos Def). The 2015 movie Straight Outta Compton was one of the largest grossing films of the year (Axelrod and Duncan, 2015; Galuppo, 2015). In 2014 Apple, Inc. purchased the company Beats Music and Beats Electronics for \$3 Billion. The company's signature product, Beats Headphones, carried the endorsement of rapper and company co-founder Andre Young (aka Dr. Dre). The deal represented Apple's biggest acquisition and is a testament to the mainstream appeal of hip-hop. Hip-hop is ubiquitous in modern American culture. It is pervasive in television, movies, magazines, video games, and on social media. In fact, it is difficult to consume any significant amount of broadcast media without being exposed to it. So, the authors' claim that hip-hop exists at the fringes of modern society lacks face validity.

\section{Challenge \#5: Mistaken (Cultural) Identity?}

The fifth challenge is the authors" claim that, "Hip hop is the culture of urban marginalized youth" (p. 2). While we do not reject this idea in toto, we do suggest that it is underdeveloped and not well supported. The authors do not explain how hip-hop culture is bounded. They do not describe the spaces in which this culture is enacted. They provide a clear 
sense of neither who the participants in this culture are nor how they come to be participants. Are all urban (or marginalized, or minoritized, or hip-hop, or Asian, etc.) youth participants in this culture? By what criteria are they considered participants? At what point are they no longer considered participants? Is participation restricted to youth? How is hip-hop culture situated in relation to youth culture broadly? Answers to these questions have implications for the veracity of the arguments on which HHBP scholarship is based and also for the application of HHBP scholarship to practice.

As it pertains to people of African descent, Shockley (2014) challenges the idea that hiphop is the culture of African youth by adopting an Afrocentrist perspective to argue that the historical enslavement and colonization of African people is a culture-interrupting episode. He maintains that as part of this episode, (a) whites have foisted myriad names, designations and cultural traits upon African people; and (b) when African people accept these alien names, designations and cultural traits they are exhibiting a form of identity confusion. Shockley's argument rests on a notion of culture that is more fixed and stable as opposed to a view of culture that is in constant flux (e.g. Nagel, 1994). Whether or not one agrees with Shockley's "stable culture" argument, his position draws our attention to the messiness of culture. In doing so, it highlights the profound oversimplification of this claim, which is supported neither empirically nor theoretically.

Closely related to the authors' claim that, "Hip hop is the culture of urban marginalized youth," is a pervading implication that urban (or marginalized, or minoritized, or hip-hop, or Asian, etc.) youth are the arbiters of hip-hop culture. Throughout the article, the authors present hip-hop culture as something that belongs to urban youth. Phelps-Moultrie (2014) challenges this idea in an essay wherein she draws extensively from archival evidence, popular media sources, 
interviews and traditional scholarship to demonstrate that there is relatively little warrant for concluding that "urban youth" should be considered arbiters of hip-hop culture. Nearly every aspect of the industry (including, but not limited to: production, distribution, publishing, labeling, merchandising, management and even consumption) is dominated by middle to upper class, white males, who would not typically be characterized as "youth." Taken together, Shockley's (2014) and Phelps-Moultrie's arguments acknowledge the role African Americans played in creating hip-hop. However, these arguments suggest that instead of regarding hip-hop as the culture of urban youth, in our current context, it might be more accurate to understand it as a set of cultural practices given to (or imposed on) urban youth.

\section{Contradictions}

\section{Challenge \#6: Internal Inconsistency}

The sixth challenge is the high degree of internal inconsistency found within the article. Rather than address every instance of internal inconsistency, we provide three examples. The first example is the framing of the article. In the abstract, the authors describe the article as a presentation of empirical research. In describing the research design, they write, “...we examined qualitative data illustrating the enactment of hip-hopness or a hip-hop identity in urban science classrooms" (p. 1). In describing their findings, they write, "The findings indicate that when teachers bring hip-hop into their science instruction, certain markers of interest and involvement that were previously absent from science classrooms become visible" (p. 1). By contrast, when describing the goals of the article, the authors suggest that the article is not a presentation of empirical research. They write, "To meet this goal, we take a conceptual approach to hip-hop and urban science education, rather than present an empirical study" (pp. 34). 
In a second example of internal inconsistency, the authors seem to vacillate on the relationship between rap and hip-hop. In one instance, the authors identify rapping as a significant component of hip-hop (p. 4). In another instance, they present rap as an example of "a number of practices perceived or defined as hip-hop that are completely separate from it" (p. 6). A third example centers around the role identity of students who participate in hip-hop culture as it pertains to school. In one instance, the authors argue that if students' "forms of capital are either devalued or misaligned to that of the teacher and the academic discipline, certain school identities are formed" (p. 8). The authors go on to suggest that “...students form anti-school identity by actively resisting academic success" (p. 8). In another instance, the authors argue that, “...the pervasiveness of the negative associations between urban youth and hip-hop, and the long standing correlation of hip-hopness to a disconnection from science and school are unwarranted" (p. 12).

\section{Challenge \#7: Can't We All Get Along?}

The seventh challenge is the authors' characterization of hip-hop as a racially unifying force. They describe hip-hop as a culture embraced by young people of varying racial and ethnic backgrounds, which has the power to minimize racial and ethnic differences among the participants. In one instance, the authors suggest that,

One of the chief characteristics of hip-hop is the strong ties that participants in the culture have to one another and the emotions that they exhibit towards one another.

The shared connections to hip-hop function to minimize ethnic or racial differences by allowing people from varying backgrounds to focus on conjoined experiences such as being socioeconomically disadvantaged or from a certain neighborhood, rather than their differences. (p. 7) 
Here again, the contradiction is palpable. There is no widespread and clearly identifiable interracial harmony among urban youth. In fact, there is good evidence that millennials, who comprise a significant percentage of hip-hop consumers (Bialik, 2005; Hart, 2009) manifest the same racially derogatory perspectives as their parents and grandparents before them (Gordon, 2015; Love, 2016).

\section{Challenge \#8: The Unfounded Perceptions of Hip Hop's Negative Impact}

The eighth challenge is the authors' characterization of the influence of hip-hop as benign. Here the authors write, “...hip-hop is often perceived as a contemporary musical form that has a negative impact on youth. However, these perceptions of hip-hop are largely unfounded, and are a result of highly visible and media-generated images of the culture" (p. 8). Contrary to the authors' dismissal, there is a substantial body of work that provides empirical demonstration of the "negative" content of hip-hop messaging as well as the "negative" influences that hip-hop can have on both thinking and behavior. In a study of the relationship between hip-hop and domestic violence, Cundiff (2013) found a positive correlation between hip-hop consumption and misogynistic thinking. In a study of the prevalence of alcohol brand references, researchers found that music characterized as "urban" had the highest percentage of alcohol references and the references are overwhelmingly positive or neutral (Siegel et al., 2013).

In a qualitative content analysis of popular music, Primack, Nuzzo, Rice, and Sargent (2012) found that 1 in 5 songs had explicit references to alcohol. Of these explicit references, the majority were positive references. The references also associated alcohol with wealth, sex, partying, other drugs and with vehicles. Although the researchers examined songs from multiple genres, the majority of songs that made reference to alcohol were in the genres of rap (63\%) or R\&B/hip hop (24\%). In a study of the impact of rap music video exposure on health risk 
behavior, researchers found that “....adolescents who had greater exposure to rap music videos were 3 times more likely to have hit a teacher, more than 2.5 times as likely to have been arrested; 2 times as likely to have had multiple sexual partners; and more than 1.5 times as likely to have acquired a new sexually transmitted disease, used drugs, and used alcohol over the twelve-month follow-up period" (Wingood et al., 2003, p. 438).

Other studies have found that hip-hop messaging is inordinately violent (Jones, 1997) and misogynistic (Hunter and Soto, 2009); that hip-hop consumption correlates positively with materialism and conspicuous consumption (Podoshen, Andrzejewski, and Hunt, 2014); that females exposed to hip-hop are more receptive of dating violence (Johnson, Adams, Ashburn, and Reed, 1995); that exposure to hip-hop predisposes young African American males to be more accepting of violence and less confident in academic pursuits (Johnson, Jackson, and Gatto, 1995); that college students exposed to hip-hop reflect more misogynistic attitudes (Kistler and Lee, 2010); and that among middle school students hip-hop leads to an overvaluation of material possessions and the ability to entertain and an undervaluation of intellectual behavior (Davis, 2014).

\section{Hip-Hop as an Instrument of Systemic Racism: Racial Propaganda}

Propaganda works best when those who are being manipulated are confident they are acting of their own free will.

- Joseph Goebbels

In sum, Emdin and Lee (2012) offer a narrative that presents hip-hop as a subculture started by "minoritized" young people in response to being locked out of mainstream social structures. The narrative suggests that the hip-hop subculture is a melting pot, which welcomes participants from many racial and ethnic backgrounds. These participants are drawn together by 
their shared experience of being marginalized in various ways and hip-hop offers a vehicle through which their voices can be heard. Using this narrative as a starting point, Emdin and Lee suggest that educators can better serve students by creating space for this subculture in traditional educational settings.

As mentioned previously, the narrative offered by Emdin and Lee (2012), is reiterated in a broad array of scholarship (e.g. Biggs, 2011; Bridges, 2011; Cermak, 2012; Hill, 2009; Jenkins, 2011; Ladson-Billings, 2013; Petchauer, 2011, 2012; Pulido, 2009; Stovall, 2006). And while we would not suggest that it is completely inaccurate, we do suggest that the supports for this narrative present multiple challenges. We also suggest that this narrative lacks explanatory power in that it is not informed by an acknowledgement of the ways that hip-hop is used as an instrument of systemic racism.

We offer an alternative narrative. This alternative narrative presents hip-hop as an instrument of systemic racism: one that serves as a propaganda vehicle to establish in the minds of the world population who African people are and how they should be understood. As a propaganda vehicle used to denigrate people of African descent, hip-hop culture and its associated musical genre are wholly controlled by whites (Rebollo-Gil and Moras, 2012). The messaging found in hip-hop music (Mutegi et al., 2014), videos (Johnson, Jackson, et al., 1995), magazines (Oredein and Lewis, 2013), and websites (Hitchens, 2015) is overwhelmingly negative, especially where it is used to characterize people of African descent. The white controllers of hip-hop culture disallow messaging that advocates violence against police and other whites, but have no such prohibitions against messaging that advocates violence against Blacks (Phelps-Moultrie, 2014).

Because hip-hop is a propaganda vehicle, it is often misrepresented as a despised 
subculture (or genre) existing on the fringes of American society despite the fact that it permeates so much of American (if not world) popular culture. This misrepresentation helps to hide the hand of those who control the industry. The heralded divide between "commercial" hiphop and "non-commercial" hip-hop serves much the same function. It allows advocates to dismiss the offensiveness of hip-hop as "commercial," despite the facts that (a) there is no clear distinction between commercial and non-commercial hip-hop, and (b) what is dismissed as "commercial" hip-hop is the exact music that exerts such a profound and detrimental influence over people's thinking and behavior.

\section{Using Hip-Hop Based Pedagogy to Counter Systemic Racism}

Our interest in this topic is driven by our respective interests in race liberation for people of African descent. It is our contention, that when educators (researchers, practitioners, or other stakeholders) advocate injudiciously for the implementation of hip-hop based pedagogy in schools, students of African descent are made even more vulnerable. We regard the alternative narrative as a starting point for HHBP research and practice that avoids making students of African descent more vulnerable and is instead liberating for people of African descent.

In terms of research, studies around HHBP should be driven by critical questions. Given the various ways that hip-hop has been shown to impact thinking and behavior broadly, to what degree does it impact students' thinking and behavior in traditional school settings? Do references to hip-hop in the form of analogies, exemplars, data sets, etc. have a priming effect on students' thinking and behavior? Do these references influence students' (or teachers') perceptions of people of African descent? If so, in what ways? What pedagogical approaches position students to be cognizant and critical of hip-hop as a propaganda vehicle? What types of ideas or experiences can serve as protective factors against the propaganda effect of hip-hop? As 
students of African descent come to schools with widely varied backgrounds, how do they respond differently to HHBP?

In terms of practice, efforts to address HHBP in traditional school settings should be aimed at helping students to recognize the propaganda function of hip-hop (and in fact all media). In this vein, pedagogy should be aimed at guiding students as they work to understand the internal structure of the entertainment industry, as well as the interaction between the entertainment industry and other elements in society. Pedagogy should also work to help students identify similarities and differences in the propaganda to which they are exposed and the propaganda used historically to shape public thinking and behavior. Students should be encouraged to raise and pursue answers to critical questions such as, "Whose interests are served by hip-hop? How are profits from hip-hop distributed? Why and in what ways do hip-hop lyrics and other forms of hip-hop messaging shape behavior?"

We agree with the authors when they write, "For students who have traditionally been marginalized in the education system, effective instruction must incorporate their interests..." (Emdin and Lee, 2012, p. 2). We can think of no better way to incorporate the interests of students of African descent than to arm them against the onslaught of systemic racism. 


\section{References}

American Association for the Advancement of Science. (1993). Benchmarks for scientific literacy. New York, NY: Oxford University Press.

Axelrod, J., \& Duncan, J. (2015). The movie Straight Outta Compton has grossed more than ninety-three million dollars since it opened last weekend. CBS Evening News.

Barton, A. C. (2002). Urban Science Education Studies: A Commitment to Equity, Social Justice and a Sense of Place. Studies in Science Education, 38, 1-37.

Bhattacharyya, S., Mead, T. P., \& Nathaniel, R. (2011). The influence of science summer camp on African-American high school students' career choices. School Science and Mathematics, 111(7), 345-353.

Bialik, C. (2005, May 5). Is the conventional wisdom correct in measuring hip-hop audience?, The Wall Street Journal.

Biggs, C. D. (2011). Sung Solecisms: Hip Hop as Non-Prescriptive Pedagogy. ScholarPractitioner Quarterly, 5(1), 39-51.

Bridges, T. (2011). Towards a pedagogy of hip hop in urban teacher education. Journal of Negro Education, 80(3), 325-338.

Cermak, M. J. (2012). Hip-hop, social justice, and environmental education: Toward a critical ecological literacy. Journal of Environmental Education, 43, 192-203.

Cohen, G. L., Garcia, J., Purdie-Vaughns, V., Apfel, N., \& Brzustoski, P. (2009). Recursive processes in self-affirmation: Intervening to close the minority achievement gap. Science, $324,400-403$.

Cundiff, G. (2013). The influence of rap/hip-hop music: A mixed-method analysis on audience perceptions of misogynistic lyrics and the issue of domestic violence. The Elon Journal 
of Undergraduate Research in Communications, 4(1), 71-82.

Davis, J. L. (2014). The Influence of hip-hop on African American youth in a poor and workingclass urban community and the use of hip-hop in school. African American Learners, $3(1-2)$.

Davis, J. L., Pitts-Bannister, V. R., \& Mutegi, J. W. (2014). Hip-hop and mathematics: A critical review of Schooling Hip-Hop: Expanding Hip-Hop Based Education Across the Curriculum. Journal of Urban Mathematics Education, 7(1), 96-106.

Emdin, C. (2011). Droppin’ science and dropping science: African American males and urban science education. Journal of African American Males in Education, 2(1), 66-80.

Emdin, C., \& Lee, O. (2012). Hip-hop, the "Obama effect," and urban science education. Teachers College Record, 114, 1-24.

Feagin, J., \& Elias, S. (2013). Rethinking racial formation theory: A systemic racism critique. Ethnic and Racial Studies, 36(6), 931-960. doi: 10.1080/01419870.2012.669839

Fuller Jr., N. (2016). The united independent compensatory code/system/concept: A textbook/workbook for thought, speech, and/or action for victims of racism (white supremacy) (Revised/Expanded ed.). (n.p.): Author.

Galuppo, M. (2015). Box office milestone: Straight Outta Compton crosses \$200M worldwide. Online Article Retrieved from www.hollywoodreporter.com

Gay, G. (2010). Culturally responsive teaching: theory, research, and practice (2nd ed.). New York: Teachers College Press.

Gordon, T. (2015, January 26). Studies reveal so-called 'racially progressive' white millennials are not so different from the racist generations that came before them, Atlanta Black Star. Retrieved from http://atlantablackstar.com/2015/01/26/studies-reveal-called-racially- 
progressive-white-millennials-different-racist-generations-came/

Gosa, T. L., \& Fields, T. (2012). Is hip hop education another hustle? The (ir)responsible use of hip hop as pedagogy. In B. J. Porfilio \& M. Viola (Eds.), Hip-hop(e): The cultural practice and critical pedagogy of international hip-hop (Vol. 56, pp. 195-210). New York: Peter Lang.

Hart, W. E. (2009). The culture industry, hip hop music and the white perspective: How onedimensional representation of hip hop music has influenced white racial attitudes. (Master of Arts in Sociology), University of Texas at Arlington.

Hill, M. L. (2009). Wounded healing: Forming a storytelling community in hip-hop lit. Teachers College Record, 111, 248-293.

Hilliard, A. G. (1988). Conceptual confusion and the persistence of group oppression through education. Equity and Excellence, 24(1), 36-43.

Hilliard, A. G., III. (1978). Straight talk about school desegregation problems. Theory into Practice, 17, 100-106. doi: 10.1080/00405847809542751

Hitchens, B. K. (2015). CNN of the Ghetto? Analyzing Black Girls and Violence as Entertainment on WorldStar Hip Hop Video Website. Paper presented at the annual meeting of the American Sociological Association, Chicago, IL. Article retrieved from http://search.ebscohost.com/login.aspx?direct=true \&db=sih\&AN=111785774\&site=ehost $\underline{\text {-live }}$

Hunter, M., \& Soto, K. (2009). Women of color in hip hop: The pornographic gaze. Race, Gender \& Class, 16(1-2), 170-191.

Jenkins, T. S. (2011). A beautiful mind: Black male intellectual identity and hip-hop culture. Journal of Black Studies, 42, 1231-1251. 
Johnson, J. D., Adams, M. S., Ashburn, L., \& Reed, W. (1995). Differential gender effects of exposure to rap music on African American adolescents' acceptance of teen dating violence. Sex Roles, 33, 597-605.

Johnson, J. D., Jackson, L. A., \& Gatto, L. (1995). Violent attitudes and deferred academic aspirations: Deleterious effects of exposure to rap music. Basic and Applied Social Psychology, 16(1\&2), 27-41.

Jones, K. (1997). Are rap videos more violent?: Style differences and the prevalence of sex and violence in the age of MTV. The Howard Journal of Communications, 8, 343-356.

Kistler, M. E., \& Lee, M. J. (2010). Does exposure to sexual hip-hop music videos influence the sexual attitudes of college students? Mass Communication and Society, 13, 67-86.

Ladson-Billings, G. (2013). "Stakes is high": Educating new century students. Journal of Negro Education, 82, 105-110.

Lee, O. (1997). Scientific literay for all: What is it and how can we achieve it? Journal of Research in Science Teaching, 34, 219-222.

Leland, J. (2012, November 18). A hip-hop experiment, The New York Times.

Love, D. (2016, October 15). In the age of Trump white millennials shatter idea that young people are progressive, Atlanta Black Star. Retrieved from http://atlantablackstar.com/2016/10/15/the-age-of-trump-white-supremacist-millennialsshatter-the-idea-that-young-people-are-progressive/

Milner IV, H. R. (2012). But what is urban education? Urban Education, 47(3), 556-561. doi: $10.1177 / 0042085912447516$

Mutegi, J. W. (2011). The inadequacies of "science for all" and the necessity and nature of a socially transformative curriculum approach for African American science education. 
Journal of Research in Science Teaching, 48, 301-316.

Mutegi, J. W. (2013). "Life's first need is for us to be realistic" and other reasons for examining the sociocultural construction of race in the science performance of African American students. Journal of Research in Science Teaching, 50, 82-103.

Mutegi, J. W., \& Pitts Bannister, V. R. (2014). Critical analysis of hip-hop pedagogy [Special issue]. African American Learners, 3.

Mutegi, J. W., Pitts Bannister, V. R., Nichols, B., Priester, D., Murdoch, Y., \& Richardson, L. (2014). Tales from the mic: A content analysis of 10 years of hip-hop lyrics. African American Learners, 3(1-2).

Nagel, J. (1994). Constructing Ethnicity: Creating and Recreating Ethnic Identity and Culture. Social Problems, 41(1), 152-176. doi: 10.2307/3096847

Oredein, T. T., \& Lewis, M. (2013). Violence in hip-hop journalism: A content analysis of the Source, A leading hip-hop magazine. Community Medicine and Helth Eduction, 3(4). doi: $10.4172 / 2161-0711.1000223$

Petchauer, E. (2011). I feel what he was doin': Responding to justice-oriented teaching through hip-hop aesthetics. Urban Education, 46(6), 1411-1432.

Petchauer, E. (2012). Sampling memories: Using hip-hop aesthetics to learn from urban schooling experiences. Educational Studies, 48(2), 137-155.

Phelps-Moultrie, J. (2014). Pedagogy of the oppressors: An examination of the white ownership and control of hip-hop. African American Learners, 3(1-2).

Podoshen, J. S., Andrzejewski, S. A., \& Hunt, J. M. (2014). Materialism, conspicuous consumption, and American hip-hop subculture. Journal of International Consumer Marketing, 26(4), 271-283. doi: 10.1080/08961530.2014.900469 
Primack, B. A., Nuzzo, E., Rice, K. R., \& Sargent, J. D. (2012). Alcohol brand appearances in US popular music. Addiction (Abingdon, England), 107(3), 557-566. doi: 10.1111/j.13600443.2011.03649.x

Pulido, I. (2009). "Music fit for us minorities": Latinas/os' Use of Hip Hop as Pedagogy and Interpretive Framework to Negotiate and Challenge Racism. Part of a special issue: Hip Hop and Social Justice Education, 42(1), 67-85.

Rebollo-Gil, G., \& Moras, A. (2012). Black women and black men in hip hop music: Misogyny, violence and the negotiation of (white-owned) space. Journal of popular culture, 45(1), $118-132$.

Riegle-Crumb, C., Moore, C., \& Ramos-Wada, A. (2011). Who wants to have a career in science or math? exploring adolescents' future aspirations by gender and race/ethnicity. Science Education, 95(3), 458-476. doi: 10.1002/sce.20431

Shockley, K. (2014). Theoretical musings on hip hop from an African centered perspective. African American Learners, 3(1-2).

Siegel, M., Johnson, R. M., Tyagi, K., Power, K., Lohsen, M. C., Ayers, A. J., \& Jernigan, D. H. (2013). Alcohol brand references in U.S. popular music, 2009-2011. Substance Use \& Misuse, 48(14), 1475-1484.

Stovall, D. (2006). We can relate: Hip-hop culture, critical pedagogy, and the secondary classroom. Urban Education, 41, 585-602.

Watson, D. (2011). What do you mean when you say urban? Rethinking Schools, 26(1), 48-50.

Welsing, F. C. (1995). The Isis papers: The keys to the colors. Chicago: Third World Press.

Wingood, G. M., DiClemente, R. J., Bernhardt, J. M., Harrington, K., Davies, S. L., Robillard, A., \& Hook, E. W., 3rd. (2003). A prospective study of exposure to rap music videos and 
African American female adolescents' health. American Journal of Public Health, 93(3), $437-439$. 